A Discipline-Based Teaching and Learning Center 

Gili Marbach-Ad • Laura C. Egan

Katerina V. Thompson

\section{A Discipline-Based Teaching and Learning Center}

A Model for Professional Development

照 Springer 
Gili Marbach-Ad

University of Maryland

College Park, MD, USA

Katerina V. Thompson

University of Maryland

College Park, MD, USA
Laura C. Egan

University of Maryland

College Park, MD, USA

Additional material to this book can be downloaded from http://extras.springer.com

ISBN 978-3-319-01651-1

ISBN 978-3-319-01652-8 (eBook)

DOI 10.1007/978-3-319-01652-8

Library of Congress Control Number: 2015933659

Springer Cham Heidelberg New York Dordrecht London

(C) Springer International Publishing Switzerland 2015

This work is subject to copyright. All rights are reserved by the Publisher, whether the whole or part of the material is concerned, specifically the rights of translation, reprinting, reuse of illustrations, recitation, broadcasting, reproduction on microfilms or in any other physical way, and transmission or information storage and retrieval, electronic adaptation, computer software, or by similar or dissimilar methodology now known or hereafter developed.

The use of general descriptive names, registered names, trademarks, service marks, etc. in this publication does not imply, even in the absence of a specific statement, that such names are exempt from the relevant protective laws and regulations and therefore free for general use.

The publisher, the authors and the editors are safe to assume that the advice and information in this book are believed to be true and accurate at the date of publication. Neither the publisher nor the authors or the editors give a warranty, express or implied, with respect to the material contained herein or for any errors or omissions that may have been made.

Printed on acid-free paper

Springer International Publishing AG Switzerland is part of Springer Science+Business Media (www. springer.com) 


\section{Foreword}

While teaching and learning have always been at the heart of the missions of higher education institutions, considerable interest in recent years pertains to ways to improve learning processes for both undergraduate students and graduate students. Concerns about whether students are being prepared for the lives they will lead, the employment responsibilities they will fill, and their roles in meeting the needs of society come from parents, employers, legislators, foundations, and national agencies, as well as from institutional administrative leaders, faculty members, and students themselves. These concerns have fueled growing interest in initiatives to strengthen undergraduate education, to integrate more preparation for teaching into doctoral education, and to refine curricula in order to deepen student learning outcomes. Encouraging and facilitating learning is a core mission of higher education, and the renewed interest in effectively meeting this mission is resulting in exciting initiatives across many universities and colleges.

While many higher education institutions are re-committing themselves to excellence in teaching and learning processes, the process of engaging in organizational change in support of deeper student learning is not always easy. Good intentions and innovative plans do not always achieve the full results intended. Significant change in teaching and learning processes requires the use of multiple levers for change that recognize the complexity of higher education institutions. For example, institutional leaders at all levels-presidents, provosts, deans, and department chairs-need to play a role in articulating goals, guiding action plans, and supporting faculty in their work to rethink curricula and teaching practices. The academic reward systems, particularly tenure and promotion processes, need to take into account, recognize, and reward the significant effort faculty members must invest to make major changes in their courses and teaching plans. Faculty members, as well as graduate students preparing for teaching roles, need opportunities to learn about the research on learning and on the teaching approaches that are particularly effective in supporting learning in their disciplines and fields. They also need time to integrate what is known about learning and teaching into their own teaching plans and practices. Faculty members also benefit from opportunities to interact and collaborate with colleagues engaged in similar work. Occasions to share successes 
and discuss challenges, and to engage in collegial conversations that generate new ideas, encourage individual efforts and promote institution-level innovation. To make change in their teaching, faculty members must understand and value the change that is called for and perceive that their efforts will be valued (or at least that they will not be penalized for this work, such as in tenure and promotion decisions) - and, additionally, they must understand and know how to engage in the new approaches to teaching that are being encouraged. In short, reform in teaching and learning processes requires a systemic approach that takes into account the various factors that affect the choices faculty members make about the allocation of their time and work efforts, including how they approach their roles as teachers.

For years, many universities and colleges have helped faculty members grow and improve as teachers through the efforts of institutional faculty development offices or teaching and learning centers. These offices or units have typically offered support through workshops and seminars, consulting for individual faculty members, mid-course evaluations, and, at some institutions, faculty learning communities that convene faculty members with similar interests or learning goals. The efforts of these centers and their leaders have supported faculty members striving to be excellent teachers and provided scaffolding for institutional efforts to improve teaching and learning processes. However, while such centers have done much to advance the teaching missions on their campuses, in recent years there is increasing interest in situating teaching improvement efforts more closely in the disciplinary contexts in which faculty members work. One reason for interest in discipline-based teaching initiatives and professional development is that disciplines have particular cultures that influence how faculty members engage in and organize their work, including their teaching. Furthermore, and of particular relevance to efforts to reform teaching and learning, disciplinary contexts and traditions frame the structure of the knowledge base in fields, how questions are focused and addressed, the relationships between concepts and thus the sequencing of learning processes, and the strategies to guide learning in the discipline. Thus, opportunities to interact with their disciplinary peers, or with those in related disciplines, may be more attractive and useful to faculty members interested in professional development around teaching and learning than exchanges with those situated in more distant disciplinary traditions. Furthermore, in the STEM fields (sciences, engineering, mathematics, and technology) in recent years, a new line of scholarly work has developed called Disciplinary-Based Education Research (DBER). Those prepared as DBER scholars deeply understand their disciplines, while also having thorough knowledge of teaching and learning processes, and particularly of the issues, questions, and challenges pertaining to teaching and learning in their specific disciplines. The increasing number of DBER scholars situated in universities and colleges across the United States is supporting interest in discipline-based efforts, especially in STEM fields, to reform teaching and learning processes at the undergraduate level and, sometimes, at the graduate level.

This book by Gili Marbach-Ad, Laura C. Egan, and Katerina V. Thompson focuses on the very significant and promising trend, gathering momentum across a growing number of institutions, to organize discipline-based teaching and learning 
centers. In this book, the authors have provided a very readable and thorough examination of one such center that serves faculty members, postdoctoral scholars, and graduate students. The book is organized into six chapters, beginning with a chapter that offers an explanation of and rationale for discipline-based professional development. Chapters 2, 3, 4 and 5 then explain the work, activities, and resources of the particular center that serves as a case study. Chapter 2 discusses how the center uses visiting teachers and scholars as well as seminars and workshops to support discipline-based professional development. Chapter 3 discusses strategies for acculturating new faculty members, while Chapter 4 addresses how the center provides consultation to individuals and groups of faculty. Chapter 5 focuses on strategies particularly organized to prepare graduate students for their responsibilities and roles as teachers. The final chapter makes a compelling case for the importance of evaluating teaching and learning centers, and offers strategies for conducting such evaluation.

Several themes weave throughout the book and enrich its contribution to readers. First, an overarching theme is that change in higher education requires a systemic approach and that universities and colleges should recognize faculty members as essential change leaders in efforts to reform and improve the educational mission. However, to engage in their roles as change leaders, faculty members must have the knowledge and expertise to guide their work. Since preparation for teaching responsibilities has not traditionally been part of academic preparation, current faculty members need specific and systematic support. Future faculty (today's graduate students) also benefit from opportunities to develop as teachers, as part of the graduate experience.

Second, preparation and professional development focused on teaching should be supported by theory, literature, and research. Much is known (and the research is expanding continuously) about learning processes, as well as about effective teaching. Discipline-based education research (DBER) is adding important insights into learning and teaching within specific disciplinary contexts. This book effectively draws on these bodies of research and literature and shows how such research can directly inform and guide the strategies used by a discipline-based teaching and learning center. The authors use the concept of pedagogical content knowledge (PCK) - attention to the intersection of what is taught (content), how it is taught (pedagogy), and the context in which it is taught - as the guiding framework for the book. Throughout the volume, they highlight five components of PCK (i.e., knowledge of student understanding of science, knowledge of science curriculum, knowledge of instructional strategies, knowledge of assessment of student learning, and orientation to science teaching) and effectively use these components as the organizing structure for their chapters. This approach emphasizes consistently that the design and work of a teaching and learning center is most effective if the center is informed by research and theory.

The third theme that is highlighted throughout each chapter is that the improvement of teaching and learning requires carefully planned practical interventions and strategies. Building on theory, research, and a clear conceptual framework, the authors allocate half of each chapter to extensive explanation and rationale for each 
professional development strategy they recommend. These detailed descriptions of the creative programs, resources, and services they offer in their center provide an excellent template to inspire the work of those starting similar centers. An implied message is that those engaged in designing professional development for faculty members and graduate students are wise to recognize that careful planning ensures that those participating will find their time was used efficiently and effectively, and that the investment was worthwhile. Such attention to the practicalities of planning innovative and effective programs is evident throughout this volume.

Finally, Marbach-Ad, Egan, and Thompson show that teaching, like research, is a scholarly activity that deserves serious, sustained intellectual engagement. Their goal, they explain, is to help current and future faculty members shape identities as what they call "reflective, reform-minded teachers." In this well-argued volume, informed by theory and research and attentive to the importance of carefully designed practice, they show how discipline-based professional development can serve as a powerful and effective lever for guiding faculty members toward identities that include commitment to effective and reflective teaching. The map they provide for creating discipline-based professional development should inspire collaborative efforts among colleagues at other institutions-including institutional administrative leaders, discipline-based education researchers, and faculty developers, as well as faculty members and graduate students - to design innovative approaches to improve teaching and learning. The students we all serve will benefit.

Professor, Higher, Adult, and Lifelong Education

Ann E. Austin

Michigan State University

East Lansing, MI 


\section{Acknowledgment}

This book, and even more so the success of the Teaching and Learning Center (TLC), is the product of the efforts of many people. While we cannot list everyone, we would like to thank all of the people who have contributed to the TLC and to the writing of this book.

First and foremost, we are deeply grateful to the undergraduate students, graduate students, postdoctoral fellows, and faculty members of the University of Maryland. They have inspired our work and been key collaborators throughout. Much of what we share in this book grew out of their ideas, feedback, and willingness to participate in our professional development and research activities. We would also like to thank the leadership of the College of Chemical and Life Sciences and the College of Computer, Mathematical and Natural Sciences, particularly Norma Allewell, Robert Infantino, Jayanth Banavar, Joelle Presson, and the current and former department chairs Norma Andrews, Michael Doyle, William Fagan, Charles Mitter, Janice Reutt-Robey, and Gerald Wilkinson. They played a fundamental role in the creation of the TLC, and have offered unwavering support for the Center and its mission of improving undergraduate instruction. We offer a special thanks to the many people from across the university with a longstanding commitment to teaching and learning. Spencer Benson, the former director of the University of Maryland Center for Teaching Excellence, was a strong supporter during the creation of the TLC and has been a frequent collaborator who was always willing to share his expertise and vision. We would also like to thank the broader science education research community, particularly the Visiting Teacher/Scholars who shared their expertise with our college community.

Additionally, we would like to thank the following individuals:

Katie Schaefer Ziemer, whose work as a graduate assistant from the creation of the TLC greatly enriched the Center's research and evaluation program

Michal Orgler, who added a valuable psychological perspective to the TLC's evaluation processes and instruments

Ann Smith, who holds great expertise in teaching, science education, and leadership, and who has tirelessly pushed us in pursuit of our mission 
Virginia Anderson and Charles Henderson, who served as external evaluators of the TLC and provided insightful feedback that contributed to refining the TLC's professional development and evaluation activities

Judy Dori, whose thorough review and thoughtful comments added to the clarity and coherence of this book

Mike Landavere, Mel Manela, and Chris Camacho, who patiently helped us overcome all of the technological obstacles we encountered

Loretta Kuo, whose graphic design adds clarity to the text

Omer Ad and Michal Ad, whose drawings, figures, and photos liven up the pages of this book

Ann Austin, who graciously contributed the foreword for this book

Bernadette Ohmer and Marianna Pascale, whose advice and support have made the book possible

Lastly, we would like to offer our thanks to our families. Their continual encouragement deepened our dedication to our work. They have lovingly supported us as we worked around the clock to do the work that we are so passionate about.

The TLC was supported by a grant from the Howard Hughes Medical Institute Undergraduate Science Education Program to the University of Maryland and by a Course, Curriculum, and Laboratory Improvement grant from the National Science Foundation (DUE-0942020). 


\section{Contents}

1 Discipline-Based Professional Development $\ldots \ldots \ldots \ldots \ldots \ldots \ldots \ldots \ldots, 1$

Transforming Undergraduate Science Education .................... 2

Active Learning and Evidence-Based Teaching Approaches.......... 2

Professional Development for Teaching in the University ............ 4

Pedagogical Content Knowledge ................................ 5

The Five PCK Components ................................ 6

PCK for the Undergraduate Level ........................... 8

Overview and Brief History of the Teaching and Learning

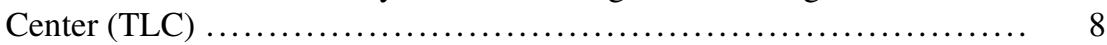

Key Contributors to a Disciplinary TLC $\ldots \ldots \ldots \ldots \ldots \ldots \ldots \ldots \ldots . . \ldots$

Institutional Levels and External Entities Involved in Change Efforts ... 11

Credibility and Buy-In .................................... 12

How to Initiate a Disciplinary TLC .......................... 14

Outline of the Book ......................................... 15

References .................................................... 16

2 Building Interest and Engagement Through Enrichment Activities ... 19

Visiting Teacher/Scholars ...................................... 19

Characteristics of Visiting Teacher/Scholars ..................... 19

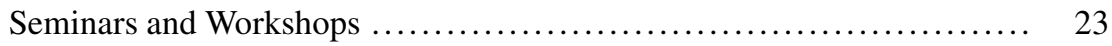

Guiding Principals in Developing Seminars and Workshops.......... 24

Selecting Seminar and Workshop Topics...................... 25

Evaluation of Seminars and Workshops ...................... 25

PCK Focus of Seminars and Workshops ...................... 25

Conclusion ................................................. 34

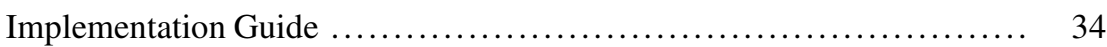

Tips for Hosting a Successful Teacher/Scholar Visit .............. 34

Example Seminars and Workshops by PCK Component ............. 35

References ............................................ 50 
3 Acculturation of New Faculty Members....................... 55

Preparation and Work Context of New Faculty Members ................ 55

Getting to Know Our New Faculty Members ...................... 56

Overview of the New Faculty Longitudinal Study ................. 57

Analysis of Study Findings by PCK Component .................. 58

Professional Development for New Faculty Members ................ 72

Welcome Workshop ...................................... 73

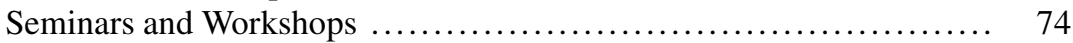

Individual Consulting .................................... 74

Connections to Networks and Faculty Learning Communities ......... $\quad 75$

Funding Opportunities ..................................... 75

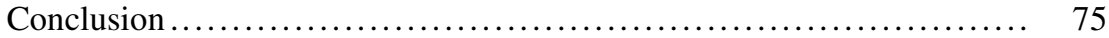

Implementation Guide .................................... $\quad 76$

Longitudinal Study: Interview Protocols ...................... 76

Welcome Workshop ..................................... 78

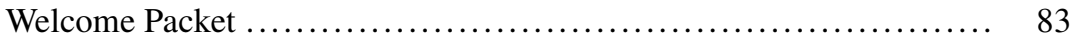

References .............................................. 85

4 Consultation for Individuals and Groups of Faculty ................. 89

The Need for Ongoing Professional Development .................. 89

Bridging the Gap Through Professional Development ................. $\quad 90$

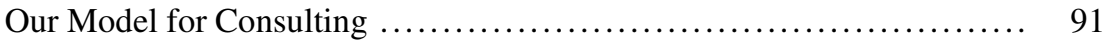

Consultation for Individuals ............................... 93

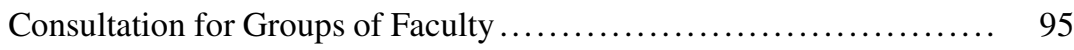

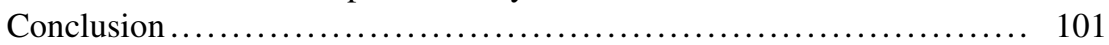

Implementation Guide ..................................... 101

Consultation for Individuals ................................ 101

Consultation for Faculty Learning Communities .................. 106

References ............................................... 110

5 Preparing Graduate Students for Their Teaching Responsibilities .... 115

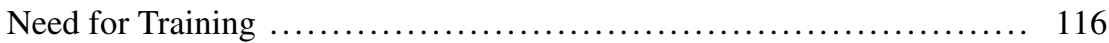

Types of Training Currently Offered ........................... 116

Short Workshops for Beginning GTAs ........................ 117

Longer Preparatory or Support Course ....................... 117

Teaching as Professional Development....................... 117

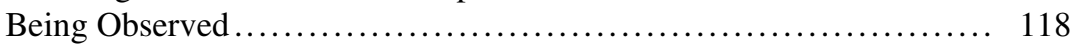

Observation of Experienced Teachers .......................... 118

Certificate Programs ....................................... 118

National Professional Development Networks ..................... 119

Professional Development for GTAs in Our University ............... 120

Needs Assessment ......................................... 120

Our Professional Development Programs for GTAs ................ 122

Conclusion .................................................. 131 
Implementation Guide ................................... 132

Workshop: The Role of the GTA ............................ 132

Mandatory Six-Week Teaching Preparatory Course ............... 134

2-Credit Course for Graduate Students ......................... 146

References ...................................................... 179

6 Evaluating the Effectiveness of a Teaching and Learning Center ...... 185

The Role of Comprehensive Program Evaluation .................. 185

Needs Assessment: A First Step ............................... 186

Stakeholders and Their Input into the TLC Needs Assessment ....... 187

Final Steps of the Needs Assessment Process.................... 192

Ongoing Evaluation: Measuring Five Levels of Program Impact......... 193

Level 1: Participation .................................... 194

Level 2: Satisfaction ..................................... 200

Level 3: Learning ........................................ 203

Level 4: Application ..................................... 205

Level 5: Impact ......................................... 211

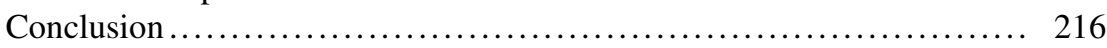

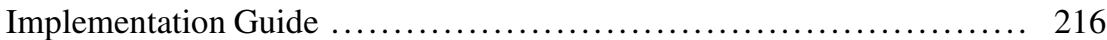

Guiding Questions for Departmental Meetings—Needs Assessment.... 216

Sample Completed Faculty Learning Community

Observation Protocol .......................................... 217

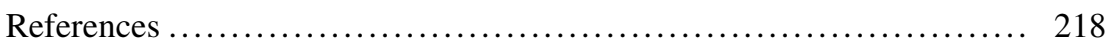

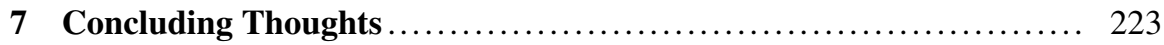

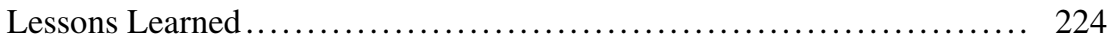





\section{About the Authors}

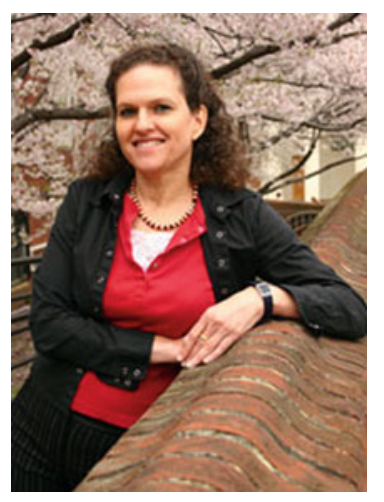

Gili Marbach-Ad is a Research Associate Professor and the Director of the Teaching and Learning Center in the College of Computer, Mathematical, and Natural Sciences at the University of Maryland. She holds B.S. and M.S. degrees in Biology from Tel Aviv University. She received her Ph.D. in Science Education in 1997 from Tel Aviv University; the subject of her dissertation was "Students' Conceptions in Genetics." She has been involved in numerous aspects of science education, including the development of study tools (science curricula, learning materials, computer software), and the training of pre- and in-service teachers through courses she has taught at Tel Aviv University. From 2000 to 2006, Marbach-Ad was a faculty member, head of the Life-Science Education Division with a tenure position in the Department of Science Education at Tel Aviv University. She joined the University of Maryland faculty in 2004. Currently, her research focuses on three topics: defining student conceptions and assessing curricular and pedagogical reforms; implementing active-learning approaches in science courses; and building a model for teacher preparation programs. Marbach-Ad publishes regularly in top peer-reviewed journals in the field. (For more biographical information, go to cmns-tlc.umd.edu/tlc/gilimarbachad.) 


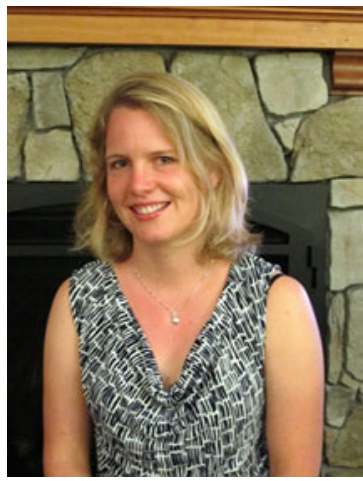

Laura C. Egan is a doctoral student in Teaching and Learning, Policy and Leadership, with a specialization in Education Policy, at the University of Maryland. As a doctoral student, she has served as graduate research assistant in the Teaching and Learning Center in the College of Computer, Mathematical, and Natural Sciences. Prior to coming to the University of Maryland, Laura earned a B.A. in Political Science and Spanish from Wake Forest University and an M.A. in Development Management and Policy from the University of San Martín in Buenos Aires. Laura has worked in research and evaluation positions at all levels of the educational system. Currently, she is a Research Associate at Westat, where she is Project Director for an education study. Laura's research interests focus on how research can inform education policy, and the relationship between policy design, policy implementation, and educational outcomes.

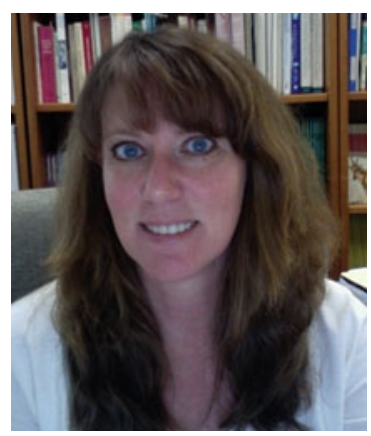

Katerina V. Thompson is Director of Undergraduate Research and Internship Programs in the College of Computer, Mathematical, and Natural Sciences at the University of Maryland. She holds B.S. and M.S. degrees in Biology from Virginia Tech and a Ph.D. in Zoology from the University of Maryland. She is also a Smithsonian Institution Research Associate in the Department of Reproductive Sciences, National Zoological Park, where her research interests focus on social influences on reproductive behavior and physiology. In addition to facilitating student involvement in cocurricular experiences, she coordinates externally funded curriculum development initiatives in the biological sciences and oversees the CMNS Teaching and Learning Center, which provides professional development opportunities for science faculty and graduate students. She has served as PI or Co-PI on science education grants from the Howard Hughes Medial Institute (HHMI) and the National Science Foundation (NSF). Her science education research focuses on strategies for facilitating student success and teaching reform in higher education. 